\title{
O PROCESSO DE PRODUÇÃO DOS ALIMENTOS COMERCIALIZADOS NAS “CANTINAS SOLIDÁRIAS" DA UEFS.
}

\author{
Wesley Freire dos Santos'; José Raimundo Oliveira Lima²
}

1. Bolsista PIBIC/FAPESB, Graduando em Engenharia de Alimentos, Universidade Estadual de Feira de Santana, e-mail: wesley.f.engal@gmail.com

2. Orientador, Departamento de Ciências Sociais, Universidade Estadual de Feira de Santana, e-mail: joseraimundouefs@hotmail.com.

PALAVRAS-CHAVE: cantinas solidárias; segurança alimentar; economia solidária;

\section{INTRODUÇÃO}

Os serviços de alimentação produzida de forma coletiva vêm crescendo significativamente, com isso, a preocupação em se consumir alimentos que garantam os padrões higiênicos sanitários cresce na mesma proporção. É de grande importância que os estabelecimentos que realizam esse serviço possuam condições mínimas essenciais para garantir ao consumidor qualidade e segurança alimentar, para isso existem medidas de fiscalização que requerem vigilância no processo produtivo, desde a seleção das matérias primas até o consumo. De acordo com a Organização Mundial de Saúde (OMS) 60\% das doenças relacionadas à origem alimentar são ocasionadas por microrganismos presentes nos alimentos, onde esta contaminação está diretamente relacionada à manipulação e preparo dos alimentos (RÊGO et al.,2001). Nesse contexto, o objetivo desse trabalho é discutir o processo de produção dos alimentos comercializados nas "CANTINAS SOLIDÁRIAS" DA UEFS (Localizadas nos Módulos I e VII).

Com a finalidade de garantir na Universidade Estadual de Feira de Santana (UEFS), um espaço de consumo, produção e comercialização de alimentos saudáveis e de práticas solidárias do trabalho, inserção do trabalho autogestionário sem que haja relação de opressão, levando em consideração o saber popular de cada sujeito, a Incubadora de Iniciativas da Economia Popular e Solidária, desenvolve no espaço das Cantinas do Módulo 01 e 07 da UEFS um projeto intitulado Cantina Solidária. Trata-se de grupos informais, ou seja, grupos de atores marginalizados socioeconomicamente no sistema formal de economia, onde os envolvidos trabalham diretamente com manipulação de alimentos da culinária, regional, local e lanches em geral que favorece a comunidade acadêmica, mediante o contato direto com produtos oriundo da agricultura familiar e serviços da Economia Popular e Solidária, buscando, então, proporcionar aos envolvidos no projeto uma aprendizagem que fortalece o diálogo entre os saberes científico e o popular, na perspectiva do trabalho coletivo, da cooperação, associação, solidariedade, com foco no desenvolvimento de ações de capacitação profissional dessa economia. As práticas vivenciadas nas Cantinas Solidárias da UEFS, contudo, contribuem diretamente para a autonomia dos sujeitos envolvidos, bem como para o desenvolvimento local, pois segundo Amaro (2009) este está diretamente ligado à melhoria das condições de vida de uma comunidade local, fazendo com que o processo de descentralização industrial aconteça de maneira mais eficaz e assim garanta a valorização do produto local, também incentivando as práticas saudáveis de alimentação compreendendo o uso de alimentos variados, seguros, que respeitem a cultura local. A elaboração de cardápio adequado é feita de modo a promover hábitos alimentares saudáveis, respeitando-se os 
hábitos alimentares de cada localidade, sua vocação agrícola e preferências por produtos do meio, dando prioridade, dentre esses, aos semi-elaborados e aos "in natura".

\section{METODOLOGIA}

A proposta metodológica deste trabalho é avaliar os produtos comercializados nas Cantinas Solidárias da UEFS dentro da pratica da economia popular e solidária no processo educativo de acompanhamento dos grupos, onde os sujeitos envolvidos nesse trabalho passam de coadjuvantes e reprodutores desse sistema explorador para protagonistas construtores da sua própria história de libertação e busca da autonomia, pois para Brandão (1996) não existe somente uma educação e tão pouco só um educador, a educação existe em todos os lugares e em todos os momentos, aprendemos com o professor, a família, os amigos, a sociedade e até com o meio. Desta forma nos deixa claro que nosso objetivo é possibilitar que os sujeitos da pesquisa influenciem e sejam influenciados pela mesma.

Desenvolveu-se consulta e seleção de referencias da área na perspectiva da investigação em busca de adquirir informações relevantes sobre as Boas Práticas de Manipulação dos Alimentos, bem como temas direcionados a Economia Popular e Solidária. Utilizou-se o método de avaliação dos procedimentos realizados que são desenvolvimentos de maneira inadequada nas Cantinas Solidárias, estimulando e estabelecendo os adequados padrões higiênico-sanitários para que a produção dos alimentos comercializados seja de qualidade desejável buscando fortalecer a organização do trabalho coletivo além na geração de trabalho e renda na linha de produção de alimentos saudáveis. A pesquisa documental contou também com uma gama de temas relacionados à Economia Popular e Solidária, que busca um novo modo de se produzir sem que haja exploração do individuo e/ou relação de opressão, na medida em que se observaram as normas e legislações especificas.

A realização do estudo contou também com a observação, comunicação e contato direto com o público universitário, onde se pode constatar que na busca de alimentação saudável as Cantinas Solidárias tem grande importância para o fornecimento adequado desses alimentos, pois elas se caracterizam como um espaço de formação e potencialização de hábitos e práticas saudáveis, no qual a comunidade acadêmica pode usufruir desses produtos muitos deles oriundos da agricultura familiar, tornando-se um importante ambiente para se desenvolver estratégias de promoção da saúde na busca do fortalecimento da alimentação saudável.

\section{RESULTADOS}

Levando em consideração que o grupo ainda participa do processo de incubação, pode-se notar êxito em algumas práticas, bem como a produção de resultados obtidos através dessa pesquisa que é de fundamental e singular importância para os grupos, pois em umas das fases que o processo de incubação possui, é a capacitação técnica onde um dos resultados propostos foi alcançado, através da realização diversas oficinas contendo temas relacionados à Economia Popular e Solidária conforme Singer (2002), que se relaciona com o trabalho coletivo, o cooperativismo, associativismo e principalmente ao que diz respeito ao Curso de Boas Práticas de Fabricação.

Outro ponto positivo a se constatar é a prática em elaborar produtos da culinária local e regional, culminando no fortalecimento da localidade e das suas raízes conforme discute sobre o desenvolvimento local Lima (2016), afinal um dos grupos que vivencia esse processo é de origem quilombola, fazendo com experienciem uma regionalidade e ancestralidade em que se pode notar no modo da produção dos alimentos, como por exemplo, a venda de 
acarajés no campus produzidos com as formas e ingredientes identitários. Desse modo, temos ainda um grande processo a ser desenvolvido pela frente, onde os grupos incubados passaram por diversas etapas a serem realizadas o que dará a esses grupos mais autonomia aos sujeitos envolvidos com o processo.

Com efeito, conforme a pesquisa participante na visão de Brandão (2007) e buscando a interação e integração direta do pesquisador com os grupos incubados que assumem as Cantinas Solidárias, deixou-se de lado a aplicação de questionários de satisfação individual, para vivenciar no local de trabalho a produção dos alimentos. Nessas vivências, o pesquisador produzia os alimentos junto com o grupo, na busca de compreender como se dava as práticas de manuseio dos alimentos, com isso fortalecia as técnicas de manipulação, pois a "fiscalização" tornava-se direta e real, fazendo com que tanto a análise do processo de produção, como a elaboração dos produtos, armazenamento, distribuição, comercialização e consumo dos alimentos fossem discutidos e observados pelo então pesquisador-participante e pelo grupo por completo, aplicando as práticas estabelecidas pelas Boas Práticas de Manipulação dos Alimentos, tendo como resultado a intervenção direta na manipulação, afinal vivenciando as práticas com o grupo em avaliação pôde-se discutir os itens estabelecidos pelas resoluções pertinentes, tornando o ambiente de acordo com os padrões determinados, fazendo com que se insira na perspectiva metodológica da pesquisa participante, da economia popular e solidária e do desenvolvimento local conforme discute Pita, Lima, e Lima, C. E. S. (2015). Portanto, ao final desse projeto o grupo terá as oportunidades de se formalizarem ou não, cabendo a eles essa decisão tornando assim o ambiente autogestionário e fortalecendo a defesa do trabalho coletivo casando com o conhecimento popular.

\section{CONCLUSÃO}

Diante do exposto, observamos que apesar de vivermos em uma sociedade individualista, competitiva e opressora ainda temos a esperança em vivermos coletivamente e agirmos sob os princípios do trabalho coletivo, da cooperação, do associativismo, do comercio justo. Há, portanto, outra forma de produzir e comercializar com mais justiça social na busca da emancipação individual, coletiva e comunitária do sujeito.

Nesse sentido, a vivência dos/com os grupos de economia popular solidária nas Cantinas Solidárias da UEFS vem nos mostrar que é possível viver em defesa da coletividade e que juntos podemos somar forças para transformarmos o sistema que nos oprime. Essa compreensão se deu no decorrer da pesquisa participante que nos possibilitou discutir o processo de produção dos alimentos comercializados nas "CANTINAS SOLIDÁRIAS" DA UEFS.

Ao se tratar de uma alimentação saudável, onde as matérias primas para elaboração desses alimentos são oriundas de agricultura familiar, fica notória a prática da valorização do local, fortalecendo os produtos da sua localidade e região bem como o desenvolvimento local. Desse modo há uma formação de rede de comercialização e produção, trazendo a questão da relação entre rural e urbano possibilitada pelas Cantinas Solidárias, são espaços físicos dentro da UEFS, que se caracteriza em um ambiente totalmente adverso a realidade do grupo em formação. Contudo, é de fundamental importância considerar o modo distinto de vivência dos sujeitos fazendo com que essa relação campo/cidade se tornem possíveis entre si e não isoladamente. Desse modo cresce o fortalecimento dessa outra economia, sendo esse projeto uma experiência em fase de construção de um resultado concreto que podemos observar na geração de trabalho e renda, bem como no fortalecimento e troca entre conhecimento cientifico e popular no ambiente acadêmico. 


\section{REFERÊNCIAS BIBLIOGRÁFICAS}

BRANDÃO, Carlos Rodrigues. O que é Educação. São Paulo. Brasiliense, 1996.

A pesquisa participante: um momento da educação popular.

Revista Educação Popular, Uberlândia, v. 6, p.51-62. jan./dez. 2007

IEPS-UEFS. Incubadora de Iniciativas da Economia Popular e Solidária da Universidade Estadual de Feira de Santana. Feira de Santana, Bahia, 2008.

LIMA, J.R.O. Economia Popular e Solidária e desenvolvimento local: relação protagonizada pela organicidade das iniciativas. Revista Outra Economia. № 18, v.10, p.317 - 2016.

PITA, F., LIMA, J. R. O., LIMA, C. E. S. Normatizando solidariedade: experiência de construção coletiva de regras de uma cooperativa informal de Economia Solidária. Otra Economía., v.9, p.69 - , 2015.

RÊGO et al. Proposta de um programa de boas práticas de manipulação e processamento de alimentos para unidades de alimentação e nutrição. Revista Higiene alimentar, São Paulo, v. 15, n. 89, p. 22-27, 2001.

SINGER, Paul. Introdução à Economia Solidária. 1 ed. São Paulo: Perseu Abramo, 2002. 